\title{
A VIOLÊNCIA CONTRA A CRIANÇA E O ADOLESCENTE NO ARQUIPÉLAGO DO MARAJÓ (PA) E SEU DIREITO A̧O RECONHECIMENTO COMO SUJEITO DE DIREITO E DE SER PROTEGIDA E RESGUARDADA
}

\author{
Ana Elizabeth Neirão Reymão ${ }^{1}$ \\ Arnaldo José Pedrosa Gomes ${ }^{2}$
}

\section{Resumo}

$\mathrm{O}$ artigo discute a violência sexual contra a criança e o adolescente no Marajó (Pará) e a importância do direito ao reconhecimento dos mesmos como sujeitos de direito, analisando sentenças de processos judiciais de estupro de vulnerável na Comarca de Ponta de Pedras. São muitos os casos registrados na região e a pesquisa, de abordagem qualitativa, traz um estudo de caso, utilizando fontes bibliográficas e documentais. Tendo como referência a teoria do reconhecimento de Axel Honneth, o estudo mostra que são poucos os casos que chegam ao Judiciário e que as sentenças limitam-se à responsabilização penal do acusado.

Palavras-chave: Abuso sexual; Estupro de vulnerável; Axel Honneth; Marajó; Judiciário.

\section{VIOLENCE AGAINST CHILDREN AND ADOLESCENTS IN MARAJÓ (PA) AND THEIR RIGHT TO RECOGNITION AS A SUBJECT OF RIGHT AND TO BE PROTECTED}

\begin{abstract}
The paper discusses sexual violence against children and adolescents in Marajó (Pará) and the importance of the right to their recognition as subjects of law, analyzing sentences of vulnerable rape lawsuits in Ponta de Pedras. There are many cases registered in the region and the research, with qualitative approach, brings a case study, using bibliographic and documentary sources. Referring to Axel Honneth's theory of recognition, the study shows that few cases reach the judiciary and that sentences are limited to criminal liability of the accused.
\end{abstract}

Keywords: Sexual abuse; Rape of vulnerable; Axel Honneth; Marajó; Judiciary.

\section{INTRODUÇÃO}

O presente artigo discute a violência sexual contra a criança e o adolescente no arquipélago do Marajó, estado do Pará, e a importância do direito ao reconhecimento dos mesmos como sujeitos de direito, a partir da análise de sentenças de processos judiciais de estupro de vulnerável na Comarca de Ponta de Pedras.

\footnotetext{
${ }^{1}$ Economista (UFPA), Doutora em Ciências Sociais (UnB), Mestre em Economia (UNICAMP), professora do PPGD-CESUPA e da FACECON-UFPA. Grupo de pesquisas CNPq Emprego, Subemprego e Políticas Públicas na Amazônia. E-mail: bethrey@uol.com.br

${ }^{2}$ Juiz de Direito no Estado do Pará, Mestre em Direito (PPGD-CESUPA). E-mail: arnaldo.pedrosa@ bol.com.br
} 
Os dados do Atlas da Violência são preocupantes e revelam que 50,9\% dos casos registrados de estupro em 2016 no Brasil foram cometidos contra menores de 13 anos de idade (IPEA; FBSP, 2018). No Pará, a Comissão de Justiça e Paz da Conferência Nacional dos Bispos do Brasil (CNBB) denunciou 365 casos de abuso (incluindo a exploração sexual) de crianças e adolescentes nos municípios do Marajó, em 2017 (LEÃO, 2017).

A violência sexual é, ao lado do abuso físico, emocional ou psicológico e da negligência, uma das formas de violência contra a criança e/ou o adolescente, os quais trazem graves prejuízos à vida da vítima em vários aspectos, como a saúde, sobrevivência ou dignidade (WHO, 2002). Dentre as formas violência sexual, tem-se o abuso sexual e a exploração sexual comercial.

O arquipélago do Marajó se destaca por ter paisagens de beleza ímpar e por suas ricas tradições culturais, mas também pelos muitos desafios sociais e econômicos que representam para as políticas públicas. Não bastasse a pobreza e a carência de bens básicos, como educação, energia elétrica, serviços e saneamento, é uma região conhecida por vários casos de violação dos direitos de crianças e adolescentes, resultando em processos judiciais de estupro de vulnerável, analisados nesse trabalho.

O estupro de vulnerável corresponde à prática de atos de conotação sexual ou conjunção carnal, em que a vítima é menor de 14 anos, sendo crime previsto pelo artigo 217A do Código Penal brasileiro. Entende-se, no presente artigo, que suas vítimas vivem uma experiência de desrespeito, que ameaça a identidade da pessoa de forma integral.

Axel Honneth (2003) ensina que a integridade corporal do indivíduo encontra-se sujeita a padrões de reconhecimento. Esse reconhecimento depende da tríade amor, direito e solidariedade, nas quais se tem o afeto das relações pessoais, a igualdade de todos os cidadãos perante a lei e a anulação da hierarquia da escala de valores da sociedade (PINTO, 2016).

$\mathrm{O}$ reconhecimento é capaz de gerar autoconfiança, autorrespeito e autoestima. Sua ausência, em qualquer das esferas, gera uma experiência de desrespeito que ameaça a identidade da pessoa de forma integral. Na relação com o Estado, importante para essa integridade, deve prevalecer a valoração social desse indivíduo (HONNETH, 2003).

Espera-se então que esse Estado, representado nas sentenças judiciais dos processos a serem analisados, atente para essa valoração. Dessa forma, definiu-se como problema de pesquisa: "as sentenças dos magistrados contemplam o reconhecimento e encaminham as vítimas de abuso sexual para atendimento especializado?". 
A pesquisa é de abordagem qualitativa e, quanto aos procedimentos, é um estudo de caso da violência sexual contra a criança e o adolescente no arquipélago do Marajó. Considerando os objetivos propostos, trata-se de uma pesquisa exploratória e descritiva, para a descrição de fatos e fenômenos associados à atuação do judiciário paraense diante dessa violência. Como fontes de informação, foram utilizadas referências bibliográficas e documentais. Assim, foram analisas sentenças de processos judiciais na Comarca de Ponta de Pedras cujo assunto era estupro de vulnerável, consultados no Sistema Libra do Tribunal de Justiça do Estado do Pará, conforme será detalhado adiante.

O texto está estruturado em seis partes, incluindo essa introdução e as considerações finais. A seção dois traz aspectos conceituais e históricos acerca da violência sexual contra crianças e adolescentes. Na seção três faz-se breves considerações sobre a teoria do reconhecimento de Axel Honneth. A seção quatro apresenta o Poder Judiciário e o sistema de justiça na rede de proteção da criança e do adolescente no Brasil. A seção cinco apresenta a Região do Marajó e traz a análise das sentenças dos processos judiciais na Comarca de Ponta de Pedras (PA).

\section{A VIOLENCIA SEXUAL CONTRA CRIANÇAS E ADOLESCENTES}

Os números do abuso e exploração sexual de crianças e adolescentes revelam um cenário que atenta contra a dignidade humana e precisa ser enfrentado, tornando a violência sexual um fenômeno social e de saúde pública. Quando a vítima é criança, afeta seu desenvolvimento e repercute negativamente na vida adulta. Umas das consequências pode ser a falta de autoestima, uma vez que a pessoa tende a internalizar uma imagem negativa de si (SARMENTO, 2016).

O abuso sexual é uma das formas de violência contra a criança e/ou adolescente, ao lado do abuso físico, emocional ou psicológico e da negligência (WHO, 2002). Ele pode ser definido como:

qualquer ato ou contato sexual de adultos com crianças ou adolescentes, com ou sem o uso de força ou violência, que pode ocorrer num único ou em vários episódios, de curta ou longa duração, e que resulta em danos para a saúde, a sobrevivência ou a dignidade da vítima (EISENSTEIN, 2004, p. 26). 
Como se observa, o significado de abuso sexual envolve o contato ou qualquer ato sexual $^{3}$ com crianças ou adolescentes, frequente ou não, e que prejudica a vida da vítima em qualquer aspecto, como a saúde, sobrevivência ou dignidade.

Dentre as características dessa violência, ressalta-se que a ameaça permanece no ar, havendo formas verbalizadas ou não-explícitas de dominação sexual do(a) menor, envolvendo um silêncio em torno do perpetrador ou da família ou do fato em si. Eisenstein (2004, p. 26) destaca que "esse trauma pode se tornar um tabu, que não é denunciado, sendo difícil de ser questionado, avaliado ou interrompido pelo profissional de saúde que venha a suspeitar desse diagnóstico".

Dessa forma, é um acontecimento muito complexo e multifacetado, alcançando todas as camadas sociais. Quando atinge pessoas mais pobres, piora as já precárias condições de sobrevivência causadas pela má distribuição da renda e de outros bens básicos, como a educação e a saúde.

Nesse contexto, as crianças e adolescentes são vítimas de uma estrutura econômicosocial de desigualdades e objeto de dominação dos adultos, ficando contaminados pela ideia de fraqueza e inferioridade. O ponto central desta violência encontra-se relacionado ao domínio do mais forte contra o mais fraco, a criança e o adolescente (RIBEIRO et al., 2004).

É um delito que está presente na vida de muitas pessoas, tanto como agressores ou como vítimas, e reproduz-se em diferentes espaços, como na família, na escola, na comunidade, trabalho e instituições.

Importante destacar que esse é um preocupante quadro que foi reconhecido apenas no século passado, tendo o abuso infantil se tornado um problema médico apenas nas últimas duas décadas. Historicamente essa categoria evoluiu da crueldade de pais e cuidadores à sexualidade e patologização do fenômeno (OLIVEIRA; RUSSO, 2017).

A violência sexual contra a criança e adolescente era, então, um problema invisível em uma sociedade de famílias fortemente influenciadas pelo modelo patriarcal e pela concepção machista, sendo as mulheres e crianças vistas como propriedade do homem, o provedor da família (MÉLLO, 2006).

\footnotetext{
${ }^{3}$ Os atos que representam o abuso sexual podem implicar contato físico ou não. O contato físico pode ser por meio de carícias, o passar das mãos em locais da zonas sexuais os seios, nádegas ou genitálias. Pode ser pela apresentação de pornografia ou, ainda, pelo ato sexual em si mesmo com a penetração anal, vaginal ou oral. Quando se manifesta sem nenhum contato físico, ocorre por abuso sexual verbal, exibicionismo ou até mesmo quando uma pessoa fica observando a criança ou adolescente em trajes mínimos ou sem roupas (EISENSTEIN, 2004; RIBEIRO et al., 2004).
} 
Porém, foi apenas na década de 1990 que o abuso sexual de crianças passou a ser considerado um problema de saúde pública, epidêmico, comparado a doenças como Câncer, Aids e cardíacas. Em 1999, a Organização Mundial de Saúde (OMS) lançou o comunicado "WHO Recognizes Child Abuse as a Major Public Health Problem”, que reforça a compreensão do abuso como problema de saúde pública em todo o mundo. Monteiro (2017, p. 120) destaca que esse é um marco do "reconhecimento oficial daquilo que vários profissionais, organizações de proteção à criança, mídia, estatísticas governamentais etc, vinham procurando demonstrar: que o abuso sexual ocorre mundialmente e era considerado um grave problema".

A posição da OMS, então, deu grande visibilidade internacional a um assunto que começou como sendo de ordem privada, assumindo esse o status de ordem pública (MONTEIRO, 2017).

Além do abuso sexual, outra forma de violência sexual contra crianças e adolescentes é a exploração sexual comercial. Faleiros (2000) define a exploração sexual comercial como o emprego de crianças e adolescentes para fins sexuais, intercedida com a finalidade de lucro, itens de valor ou outros instrumentos de trocas, tendo como principal objetivo obter ganho ${ }^{4}$. Ela pode ocorrer de quatro maneiras: prostituição, tráfico e venda de pessoas para fins sexuais, pornografia, turismo sexual.

Essas situações são incompatíveis com o que dispõe a Constituição Federal brasileira (1988) que traz, em seu artigo art. $227, \S 3^{\circ}$, o princípio da proteção integral à criança e ao adolescente, que gozam de todos os direitos fundamentais inerentes à pessoa humana. Nesse contexto, devem lhes asseguradas todas as oportunidades $\mathrm{e}$ facilidades para $\mathrm{o}$ desenvolvimento físico, mental, moral, espiritual e social, em condições de liberdade e de dignidade.

O Estatuto da Criança e do Adolescente (Lei no 8.069, de 13 de julho de 1990), por sua vez, estabelece o princípio da prioridade absoluta, em seu artigo $4^{\circ}$, parágrafo único, devendo esses terem a primazia de receber proteção e socorro em quaisquer circunstâncias e a preferência na formulação e na execução das políticas sociais públicas.

\footnotetext{
${ }^{4}$ A exploração sexual comercial, lembra o autor, é também às vezes nominada: "uso sexual de menores de idade com fins lucrativos" ou "prostituição infanto-juvenil" (FALEIROS, 2000, p. 9). Trata-se, então, de uma violência sexual praticada por adultos envolvendo o pagamento em espécie ou outra forma de retribuição ao menino ou a menina, ou a uma terceira pessoa ou várias, pela prestação do sexo. A criança e o adolescente são, assim, utilizados como objetos sexual e tratados como mercadoria.
} 
Dessa forma, a criança e o adolescente devem ser reconhecidos como sujeitos de direito. Ao serem submetidos à violência sexual, no entanto, ficam prejudicados em seu desenvolvimento saudável, o que importa graves consequências de ordem psicológica, econômica e social. Cumpre ao Estado, nesse contexto, dar total proteção aos mesmos, regulando os seus direitos e suas garantias, superando a noção de que o adulto é superior a tudo, o que historicamente vem prejudicando o pleno desenvolvimento emocional e físico de várias crianças e adolescentes e possibilitando que as transgressões contra si não sejam penalizadas e apuradas.

A teoria do reconhecimento de Axel Honneth fala sobre a necessidade de as pessoas serem reconhecidas no mundo, de se construir um significado para sua existência. De conceder identidade ao indivíduo, como explica a próxima seção.

\section{A TEORIA DO RECONHECIMENTO DE AXEL HONNETH: A LUTA PELO RECONHECIMENTO DA CRIANÇA E DO ADOLESCENTE COMO SUJEITO DE DIREITO E O ABUSO SEXUAL}

A criança e o adolescente têm o direito ao reconhecimento como pessoa sujeito de direito. No entanto, as inúmeras denúncias de violência, de maus tratos, negligência, abuso e exploração sexual, violam esses direitos e garantias e levam à ausência de reconhecimento.

A importância desse reconhecimento é destaca por Axel Honneth, cuja base da teoria é a tríade amor, direito e solidariedade ${ }^{5}$. A esfera do amor está no campo das relações pessoais, a segunda implica na igualdade de todos os cidadãos perante a lei, enquanto a terceira busca o reconhecimento que anule a hierarquia da escala de valores da sociedade. Nessa esfera, o autor pretende enfrentar o que considera uma das bases do capitalismo, uma vez que, segundo ele, à exceção da burguesia, as pessoas só têm reconhecimento pelo que conseguem alcançar enquanto cidadãos produtivos (PINTO, 2016).

Dessa forma, o reconhecimento é entendido como a possibilidade de cada um assegurar a singularidade da própria personalidade, em um contexto de aprovação social (FRASER; HONNETH, 2003). E é articulado diretamente ao sentimento de desrespeito vivenciado por classes, grupos e indivíduos (PINTO, 2016).

\footnotetext{
5 Para alguns autores, como em Pinto (2016), as três esferas do reconhecimento de Honneth são traduzidas/apresentadas como: a do amor, a da lei e a da estima. Em Sá (2014), as esferas são apresentadas como família (afeto), na sociedade civil (direito) e no Estado (solidariedade):
} 
Honneth busca apresentar, com fundamento no pensamento hegeliano, como o reconhecimento intersubjetivo é uma importante forma de autorrealização dos indivíduos e construção de uma justiça social. A vida ética, então, é composta de três momentos: família, sociedade civil e Estado. Nela desenvolvem-se relações intersubjetivas marcadas pelo amor, pelo direito e pela solidariedade. E é com esse pressuposto que Honneth desenvolve sua teoria social (SÁ, 2014).

O autor procura mostrar, por meio da desconstrução histórica, que o desenvolvimento moral implica no aumento das relações de reconhecimento, o que ocorreria, progressivamente, em três estágios ou esferas: na família (afeto), na sociedade civil (direito) e no Estado (solidariedade). No primeiro, o indivíduo é reconhecido como ser carente concreto. No segundo tem-se a relação cognitivo-formal de reconhecimento do direito, como pessoa de direito abstrata. Na relação de reconhecimento do Estado, por fim, esclarecida no plano emotivo, como universal concreto, tem-se o sujeito socializado em sua unicidade (HONNETH, 2003).

Esse reconhecimento possui três dimensões: a autoconfiança, que é adquirida pela criança nos primeiros anos de vida juntamente com a mãe; o autorrespeito, no qual se possibilita a escolha racional entre normas, o tornando digno do reconhecimento jurídico; e, finalmente, a valoração social que permite o reconhecimento de atributos genuínos pessoais ou diferenciais.

Nessa linha de argumentação, colocando no centro de sua teoria crítica os conceitos de conflito e reconhecimento, Honneth (2003) define os princípios e regras pelos quais a sociedade se desenvolve, isto é, a normatividade própria do desenvolvimento social e sua configuração moral.

Assim, o reconhecimento é tido como um fenômeno pluridimensional e não ocorre plenamente enquanto não estiverem garantidos os meios de realização plenos da individualidade. $\mathrm{O}$ reconhecimento pleno requer que seja garantida a autonomia do indivíduo em sua particularidade histórica, bem como a liberdade corpórea, a autonomia moral e a dignidade em sua individualidade.

A importância da integridade do ser humano e de livrá-los dos maus-tratos e do rebaixamento pessoal pode ser observada quando o autor afirma:

Então parece fazer todo o sentido partir de um tipo de desrespeito que toca a camada da integridade corporal de uma pessoa: aquelas formas de maus-tratos práticos, em que são tiradas violentamente de um ser humano todas as possibilidades da livre 
disposição sobre seu corpo, representam a espécie mais elementar de rebaixamento pessoal (HONNETH, 2003, p. 214-215).

Nesse contexto, o reconhecimento não denota a mera identificação do outro. Ele é associado à valorização da pessoa reconhecida, em atitude que lhe expressa o devido respeito. Sua negação equivale ao desrespeito. Trata-se de comportamento que não apenas insulta as pessoas ou lhes inflinge dano, como também degrada a sua auto imagem, para o autor. Assim, o não reconhecimento corresponde à violação, à privação de direitos e à degradação (SARMENTO, 2016).

A recusa do reconhecimento se equipara a várias formas de violência - a violação, a privação de direitos e a degradação -, explica Honneth (2003). E atinge intensamente a compreensão do indivíduo a respeito de si próprio, reproduzida nas relações intersubjetivas. Essa violência tem uma abrangência física e psíquica, provocando, também, de forma incontrolável, a violência do indivíduo contra si próprio - o sujeito sente o rebaixamento da autoestima por imposição de outrem e por elaboração própria, quando assenta em questão os valores constitutivos da confiança que edificou para si.

Esse sentimento de rebaixamento é instigado por características generalizadas da sociedade, que ameaçam ou ferem psiquicamente o indivíduo na percepção que ele tem de si mesmo. Como exemplo das múltiplas experiências de desrespeito, Honneth (2003) cita o rebaixamento que decorre da denegação de direitos básicos e a humilhação provocada pela menção pública ao insucesso de um indivíduo.

O reconhecimento, em suas três formas, se faz necessário para que o indivíduo consiga levar sua vida da maneira como a imagina para si próprio. Assim, necessita de autoconfiança, abastecida pelo reconhecimento afetivo; de segurança, qualidades de vida sólida e a autonomia jurídicas, provocadas por meio reconhecimento jurídico; e de fé a respeito do valor de suas aptidões e práticas, resultado do reconhecimento de afeto social.

O Estado é de suma importância nessa possibilidade de boa vida e para ele é conferida a empreitada de aparelhamento social com o apoio nos valores socialmente vigentes e com o objetivo de alcançar situações reais pautadas naqueles mesmos valores.

O Estado é, pois, um "parceiro de interação" distinto e imperativo: "A liberdade de autorrealização depende de pressupostos que não estão à disposição do próprio sujeito humano, visto que ele só pode adquiri-la com a ajuda de seu parceiro de interação" (HONNETH, 2003, p. 273). 
Assim, além dos sujeitos integrantes do todo social, o Estado é tido como um parceiro distinto e imperativo de interação real, necessário e importante. Cabe a ele, na visão do autor, garantir as esperanças de um sujeito em face do outro e, ainda, resguardar as expectativas do indivíduo em face do próprio Estado.

Alguns Estados, porém, não respeitam o reconhecimento, seja ele afetivo, jurídico ou o solidário. Indivíduos que estão subjugados, a todo momento, à possibilidade de desrespeito, nunca poderão experimentar a "liberdade" mencionada pelo autor, que constitui a ausência de bloqueios, inibições e angústias psíquicas. Essa liberdade, então, deve ser compreendida como uma espécie de confiança dirigida para fora, que oferece segurança ao indivíduo na aplicação de suas capacidades (HONNETH, 2003).

Estudos psicológicos mostram que indivíduos torturados e violados frequentemente sofrem "morte psíquica". No caso de privação coletiva de direitos e da exclusão social, como em situações de escravidão, emerge o conceito de "morte social". Quando o desrespeito se encontra na degradação cultural de uma forma de vida, tem-se o que Honneth (2003) chama de "vexação".

Dessa forma, tudo o que é denominado no linguajar corrente como "desrespeito " ou "ofensa" pode abarcar níveis diferentes de profundidade na lesão psíquica de um indivíduo. Por isso, entre o rebaixamento concreto ligado à denegação de direitos fundamentais rudimentares e o rebaixamento sutil que segue a referência pública ao insucesso de um indivíduo, há uma diferença categorial que precisa ser considerada (HONNETH, 2003).

No caso da violência sexual contra a criança e adolescente, tem-se uma situação de desrespeito que viola a sua identidade, podendo acarretar sérias consequências de ordem psíquicas, físicas e econômicas. Por essa razão, o ordenamento jurídico deve reconhecer a criança e o adolescente como sujeito de direito e obrigações, resguardando-lhe a dignidade da pessoa humana. Deve, então, amparar e dar total proteção aos mesmos, regulando os seus direitos e suas garantias, superando a noção de que o adulto é superior a tudo, o que pode possibilitar que as transgressões contra aqueles não sejam penalizadas e apuradas, prejudicando seu pleno desenvolvimento emocional e físico.

Nesse contexto, o Poder Judiciário, garantidor dos direitos individuais, coletivos e sociais, desempenha papel fundamental, como discute a seção a seguir. 


\section{O PODER JUDICIÁRIO E O SISTEMA DE JUSTIÇA NA REDE DE PROTEÇÃO DA CRIANÇA E DO ADOLESCENTE}

O Estatuto da Criança e do Adolescente (Lei nº 8.069/1990) elenca uma série de direitos, como o à saúde, à educação e o encaminhamento para serviços especializados, em casos de maus-tratos. Nele prevalece o princípio da tríplice responsabilidade compartilhada, segundo o qual a família, o Estado e a sociedade têm a obrigação de garantir o efetivo atendimento à criança e o adolescente.

O referido Estatuto ressalta, ainda, que as crianças e adolescentes que sofrem algum tipo de violação de seus direitos devem ser afastados de sua família, devendo a rede de atendimento e o poder público atendê-los adequadamente e socorrê-los dos maus tratos.

Fazem parte desse rede de atendimento instituições como o Ministério Público Estadual, a Defensoria Pública Estadual, advogados da Assistência Social das Prefeituras, a Delegacia de Polícia, o Conselho Tutelar e o Conselho Municipal dos Direitos da Criança e do Adolescente (CMDCA), o Centro de Referência de Assistência Social (CRAS) e o Poder Judiciário.

Esse Poder tem a função de garantir os direitos individuais, coletivos e sociais e resolver conflitos entre cidadãos, entes e Estado. Assim, estabelece a Constituição Federal de 1988 (CF/88) que o Judiciário tem como principal missão zelar por seu texto, defender a democracia e proteger os cidadãos brasileiros dos abusos cometidos pelos seus pares e pelo próprio Estado.

Dentre as instituições que atuam no enfrentamento da violência sexual, o Poder Judiciário tem importância fundamental, uma vez que a responsabilidade legal implica imputar sanção referente ao crime cometido, sendo função primordial da lei regular o comportamento dos indivíduos e da sociedade. O sistema judiciário tem como objetivo buscar a justiça social e garantir os direitos dos cidadãos (FRONER, 2008). Soma-se a isso o fato de que o processo legal estabelece responsabilidade e ajuda os agressores sexuais a assumirem a autoria e, ainda, a sentença proferida para o agressor funciona como uma forma de reparação para a vítima (FÜRNISS, 1993).

O Estado-Juiz deve suprir a vontade das partes e resolver a lide originária de um conflito de interesses, por meio da invocação da tutela jurisdicional. Destarte, o objetivo que se almeja com a ativação da justiça é a prolação de uma sentença de mérito, a qual resolve conflito de interesses, que no caso concreto do artigo implica na punição do autor pelo delito 
praticado e a proteção da vítima do abuso sexual, resguardando-lhe os direitos e dando-lhe real amparo, como parte da rede de proteção da criança e do adolescente.

Entende-se essa como uma forma de reconhecimento, à luz do que ensina Axel Honneth, cuja teoria tem como alicerce os pressupostos da tríade amor, direito e solidariedade, estando o aumento das relações de reconhecimento relacionado ao desenvolvimento moral em três estágios ou esferas: na família (afeto), na sociedade civil (direito) e no Estado (solidariedade), como já exposto.

Na relação com o Estado tem-se o sujeito socializado em sua unicidade, a valoração social, que, ao lado da autoconfiança e do autorrespeito, completa o reconhecimento e asseguram a integridade do ser humano (HONNETH, 2003).

Os magistrados, enquanto representantes do Estado, possuem uma importante ferramenta de transformação social e proteção social em análise, uma vez que a Constituição Federal vigente, em seu artigo 227, é clara ao dispor que é dever da família, do Estado (juiz) e da sociedade, resguardar toda criança e adolescente, com absoluta prioridade o direito à vida, saúde, deixar a salvo de qualquer negligencia e violência. Esses são direitos fundamentais da criança e do adolescente que devem ser instrumentalizados nas sentenças e decisões judiciais, protegendo as vítimas de abuso sexual.

A legislação infraconstitucional reforça o entendimento nesse sentido. O Código de Processo Penal, no artigo 201, $\S 5^{\circ}$ afirma que: "Se o juiz entender necessário, poderá encaminhar o ofendido para atendimento multidisciplinar, especialmente nas áreas psicossocial, de assistência jurídica e de saúde, a expensas do ofensor ou do Estado". Ou seja, encontra-se expresso nesta legislação que o magistrado (o Estado, juiz), ao se deparar com uma vítima de violência, que necessita de tratamento adequado para superar os danos decorrente da violência, deverá submetê-la a atendimento especializado.

Nessa perspectiva, buscou-se analisar algumas sentenças proferidas em processos de abusos sexual na comarca de Ponta de Pedras, no arquipélago do Marajó, região conhecida por inúmeros casos de violação dos direitos de crianças e adolescentes, como o abuso e a exploração sexual.

5 ESTUDO DE CASO DAS SENTENÇAS EM PROCESSOS JUDICIAIS DE ABUSOS SEXUAL EM PONTA DE PEDRAS, NO ARQUIPÉLAGO DO MARAJÓ 
O Marajó se destaca pela riqueza das paisagens e pela importância cultural de suas tradições, mas guarda muitos desafios sociais e econômicos. Além do grande número de pessoas pobres, a região é conhecida pela ocorrência de inúmeros casos de violação dos direitos de crianças e adolescentes, resultando em processos judiciais de estupro de vulnerável, analisados nessa seção, que traz o estudo da Comarca de Ponta de Pedras.

\subsection{O Marajó, terra de contrastes e de muitos casos de abuso sexual}

Ponta de Pedras é um dos 16 municípios do arquipélago do Marajó, composto por diversas ilhas ${ }^{6}$. Em termos administrativos, faz parte da Região de Integração (RI) do Marajó, uma das 12 do estado do Pará7.

A beleza natural desse que é o maior arquipélago fluviomarinho do planeta é ímpar, composta por campos naturais, planícies alagadas e densas florestas. Apesar da riqueza de suas paisagens e da relevância cultural de suas tradições, a RI Marajó guarda muitos desafios. Possui o menor Produto Interno Bruto (PIB) per capita do estado ${ }^{8}$, tendo a administração pública como a atividade mais relevante (42\%) para o valor adicionado do PIB da Região (FAPESPA, 2015).

Nela também se constata a maior taxa de pobreza $(57 \%)$ e a maior taxa de analfabetismo entre pessoas com 15 anos ou mais (22\%) de todo o estado do Pará. Possui 525.347 habitantes, $6,5 \%$ da população estadual, e todos os seus municípios, o percentual de pessoas inscritas no CADÚnico, que se declararam abaixo da linha da pobreza, supera os 90\%. Nove dos municípios da RI apresentaram Índice de Desenvolvimento da Educação Básica (Ideb) abaixo da meta estabelecida para o Pará (FAPESPA, 2015).

A região também é conhecida pela ocorrência de inúmeros casos de violação dos direitos de crianças e adolescentes, especialmente de abuso e exploração sexual, os quais têm sido denunciados por lideranças populares e pela Conferência Nacional dos Bispos do Brasil (CNBB) como fonte de dor e sofrimento (LEÃO, 2017).

\footnotetext{
${ }^{6}$ Os municípios da região do Marajó são: 1-Afuá, 2-Anajás, 3-Bagre, 4-Breves, 5-Cachoeira do Arari, 6-Chaves, 7-Curralinho, 8-Gurupá, 9-Melgaço, 10-Muaná, 11-Ponta de Pedras, 12-Portel, 13-Salvaterra, 14-Santa Cruz do Arari, 15-São Sebastião da Boa Vista, 16-Soure.

${ }^{7}$ As demais regiões de integração são: Araguaia, Baixo Amazonas, Guamá, Carajás, Lago Tucuruí, Guajará, Rio Capim, Rio Caeté, Tapajós, Xingu e Tocantins.

${ }^{8}$ Em 2016, o Produto Interno Bruto (PIB) per capita do estado foi de R\$16,7 mil. Na RI do Marajó, foi de R\$ 8,2 mil (FAPESPA, 2019).
} 
Dentre as complexas causas que contribuem para esse triste quadro está a pobreza. No município de Ponta de Pedras, com 30.608 habitantes, 52,21\% são residentes na zona rural, predominando os caboclos ribeirinhos de renda muito baixa, que vivem no manejo do açaí e da pecuária e possuem pequenos rebanhos de bovinos e bubalinos (FAPESPA, 2019).

O cenário de estagnação econômica e baixos índices de desenvolvimento humano são preocupantes. Os municípios da região têm os piores IDHM do Brasil, estando 14 deles, de um total de 16, nas últimas posições no ranking do IDH no país. Com excessão de Soure $(0,615)$ e Salvaterra $(0,608)$, todos os demais estão nas faixas de baixo ou muito baixo desenvolvimento humano ${ }^{9}$.

Esse pouco desenvolvimento nos municípios do Marajó, medido pelos indicadores da qualidade de vida que compõem o índice, refletem a grande carência de políticas públicas para a região. O quadro cria uma situação de vulnerabilidade para a maioria da população, encontrando terreno propício para a ocorrência de diversas mazelas sociais, dentre as quais o abuso e a exploração sexual infanto-juvenil, fazendo com que esses municípios apresentem preocupantes índices de vulnerabilidade, elevando os riscos para a violação de direitos de crianças e adolescentes.

Entre as principais causas do crescente registro desse tipo de violência estão a pobreza, a exclusão, desigualdade social, discriminação racial, de gênero e etnia. Apesar de crimes de abuso sexual contra crianças e adolescentes ocorrerem em diversos setores da sociedade, sendo pobres e ricos vítimas dessa forma de violência, grande parte das denúncias de abuso sexual são de pessoas das faixas mais baixas de renda.

Os números oficiais não representam o total de casos, no entanto. Estudos como os de Lima e Alberto (2010) mostram que famílias com pessoas de renda mais alta também têm vítimas, mas pouco denunciam. Assim, pessoas mais pobres costumam revelar mais do que as de renda média ou alta, impondo também responsabilidade aos órgãos competentes na solução do problema.

Quando os casos de abuso sexual e exploração contra a criança e o adolescente chegam ao Poder Judiciário como sistema de justiça e da rede de proteção e garantias, suas

\footnotetext{
${ }^{9}$ Soure $(0,615)$ e Salvaterra $(0,608)$ estão na faixa de médio desenvolvimento humano (DH), segundo o ranking IDHM Municípios 2010, do Atlas do Desenvolvimento Humano no Brasil 2013. Oito municípios estão na faixa de baixo DH: Ponta de Pedras $(0,562)$, São Sebastião da Boa Vista $(0,558)$, Santa Cruz do Arari $(0,557)$, Muaná $(0,547)$, Cachoeira do Arari $(0,546)$, Gurupá $(0,509)$, Breves $(0,503)$ e Curralinho $(0,502)$. Seis estão entre os 50 piores IDHM do Brasil, com muito baixo DH: Afuá $(0,489)$, Anajás $(0,484)$, Portel $(0,483)$, Bagre $(0,471)$, Chaves $(0,453)$ e Melgaço $(0,418)$.
} 
decisões e sentenças têm o dever de resguardá-las qualquer tipo de violência. É nessa perspectiva que se efetuará um estudo de caso tendo como fonte de pesquisa sentenças de magistrados na Comarca de Ponta de Pedras, no Marajó (Pará).

\subsection{Estudo de caso: as sentenças de Ponta de Pedras}

A pesquisa teve como uma das fontes de informação os processos judiciais penais de estupro de vulnerável contra criança e adolescente e as sentenças penais, consultados no Sistema Libra do Tribunal de Justiça do Estado do Pará. O levantamento abrangeu, no acervo ativo da Comarca de Ponta de Pedras, o período de 2009 a agosto de 2019 (ou seja, os 10 últimos anos). Já quanto aos processos julgados, arquivados e baixados, o período selecionado foi menor, uma vez que a consulta é mais complexa e, por falta de recursos, foi reduzido para os anos entre 2014 e agosto de 2019.

Foram encontrados 8 processos na Comarca, conforme listados no Quadro 1.

Como se observa no resumo dos fatos nele efetuado, as situações de violência envolvem crianças e adolescentes e narram atos e contatos sexuais que se caracterizam como abuso, resultando em danos para a saúde, a sobrevivência ou a dignidade da vítima (EISENSTEIN, 2004).

São tristes relatos de uma realidade cotidiana para muitos no Marajó e, como revela a última coluna do Quadro 1, dos 8 processos no acervo pesquisado da Comarca de Ponta de Pedras, tem-se apenas 2 condenações. Nos demais, não há sentença em 5 e tem-se uma absolvição.

Quadro 1 - Processos judiciais penais de estupro de vulnerável contra criança e adolescente - Comarca de Ponta de Pedras (PA) - 2009-2019*

\begin{tabular}{|c|l|c|}
\hline $\begin{array}{c}\text { NÚMERO DO } \\
\text { PROCESSO }\end{array}$ & \multicolumn{1}{c|}{ RESUMO DOS FATOS } & $\begin{array}{c}\text { SENTENÇA } \\
\text { (CONDENAÇÃO/ } \\
\text { ABSOLVIÇÃO) }\end{array}$ \\
\hline $0000439-35.2009 .814 .0042$ & $\begin{array}{l}\text { Na fase de apresentação de resposta escrita não } \\
\text { houve a instrução processual }\end{array}$ & $\begin{array}{c}\text { Não há sentença no } \\
\text { processo }\end{array}$ \\
\hline $0002988-47.2013 .814 .0042$ & $\begin{array}{l}\text { Na fase de perícia judicial para análise de possível } \\
\text { imputabilidade do acusado. Processo supenso }\end{array}$ & $\begin{array}{c}\text { Não há sentença no } \\
\text { processo }\end{array}$ \\
\hline $0004813-26.2013 .814 .0042$ & $\begin{array}{l}\text { Realizada a audiência de instrução e julgamento, } \\
\text { aguardando a apresentação de alegações finais em } \\
\text { fase de diligência na secretaria da Comarca, } \\
\text { porém na deliberação da audiência de instrução e } \\
\text { julgamento o magistrado deliberou que o CRAS } \\
\text { do município prestasse atendimento a vítima do } \\
\text { abuso (26/11/2015). Em 18/08/2016 esse pedido } \\
\text { foi reiterado, mas o momento desta pesquisa não }\end{array}$ & $\begin{array}{c}\text { Não há sentença no } \\
\text { processo }\end{array}$ \\
\hline
\end{tabular}




\begin{tabular}{|c|c|c|}
\hline & $\begin{array}{l}\text { tinha sido encaminhado o relatório de } \\
\text { atendimento e o processo está parado }\end{array}$ & \\
\hline $0004534-06.2014 .814 .0042$ & $\begin{array}{l}\text { Narra o Promotor de Justiça que, conforme } \\
\text { depoimento da vítima, o réu manteve relações } \\
\text { sexuais consigo, XXXXXXXXXX, com idade de } \\
13 \text { anos, à época dos fatos. Informou que a vítima, } \\
\text { logo após o ato, passou a ter sangramento vaginal } \\
\text { e teve que ser socorrida no hospital desta } \\
\text { comarca. Que o fato ocorreu em } 16 / 06 / 2014 \text {; que } \\
\text { a declarante estava na escola aguardando o } \\
\text { ônibus; que o acusado deu uma carona para a } \\
\text { declarante na moto; que o pneu da moto furou e o } \\
\text { acusado saiu para consertar o pneu ou obter outro } \\
\text { veículo; que a declarante ficou com o filho do } \\
\text { acusado; que meia hora depois o acusado chegou } \\
\text { em outra moto; que foram para casa do acusado e } \\
\text { tomaram café; que o acusado pediu para o filho ir } \\
\text { à casa de um vizinho entregar um carro de mão; } \\
\text { que ficaram a sós e logo depois se abraçaram, se } \\
\text { beijaram e depois aconteceu o fato; que chegaram } \\
\text { a manter relação sexual e logo depois houve um } \\
\text { sangramento e a declarante foi para sua casa; que } \\
\text { o acusado levou a declarante em casa; que ficou } \\
\text { no banheiro por algum tempo e como viu que } \\
\text { sangrava muito pediu ajuda do primo e depois a } \\
\text { tia; que após, foi levada para o Hospital; que } \\
\text { chegou a desmaiar dentro do veículo, em Antônio } \\
\text { Vieira, por causa da perda de sangue; que ficou } \\
\text { internada por 08 dias. }\end{array}$ & $\begin{array}{c}\text { Condenado a } 8 \text { (oito) } \\
\text { anos de reclusão pelo } \\
\text { crime tipificado no } \\
217-\mathrm{A} \text { do CP }\end{array}$ \\
\hline $0003370-98.2017 .814 .0042$ & $\begin{array}{l}\text { Alegou o Ministério Público que no dia } \\
\text { 14.08.2015, por volta de } 21 \mathrm{~h} \text {, Centro, neste } \\
\text { município, a vítima J.T.L., de } 8 \text { (oito) anos de } \\
\text { idade, foi abusada sexualmente pelo denunciado. } \\
\text { J.T.L., e que na data de } 14.08 .2015 \text { foi vista saiu } \\
\text { da parte de trás da casa de R N F P, companheiro } \\
\text { de sua outra irmã, assustada e chorando, e } \\
\text { escondeu-se da mãe embaixo da ponte, e ao } \\
\text { levantar sua calcinha, notou que a mesma estava } \\
\text { suja de lama. Ainda, de acordo com a referida } \\
\text { testemunha, a vítima foi levada para casa e lá } \\
\text { contou que D (acusado) puxou-lhe para dentro de } \\
\text { casa e introduziu o dedo e o pênis em sua vítima. } \\
\text { Sustentou o Ministério Público que o denunciado, } \\
\text { ao praticar ato de conjunção carnal ou outro ato } \\
\text { libidinoso com menor de } 14 \text { anos, perpetrou o } \\
\text { delito de estupro de vulnerável, tipificado nas } \\
\text { sanções do ART. 217-A C/C ART.234-B DO } \\
\text { CPB }\end{array}$ & $\begin{array}{l}\text { Condenado a } 09 \\
\text { (nove) anos de } \\
\text { reclusão pelo crime } \\
\text { tipificado no } 217-\mathrm{A} \\
\text { do CP }\end{array}$ \\
\hline 000071034.2017 .814 .0042 & $\begin{array}{l}\text { Consta na denúncia que, na data de } 26.11 .2016 \text {, a } \\
\text { vítima, XXXXXXXXX, foi estuprada pelo } \\
\text { acusado em uma casa abandonada, na rodovia } \\
\text { Mangabeira, próximo ao ramal da Praia Grande. } \\
\text { Segundo o Ministério Público, a vítima não } \\
\text { aceitou do réu o valor oferecido de } \mathrm{R} \$ 100,00 \\
\text { (cem reais), e mesmo assim o acusado praticou o } \\
\text { ato sem o consentimento da menor, que } \\
\text { engravidou em decorrência dessa conduta ilícita }\end{array}$ & Absolvição \\
\hline
\end{tabular}




\begin{tabular}{|c|l|c|}
\hline 0004971.08 .2018 .814 .0042 & $\begin{array}{l}\text { Processo em andamento. Houve apenas a } \\
\text { decretação de prisão do acusado, mas não existia } \\
\text { a proteção da vítima }\end{array}$ & Não houve sentença \\
\hline 0006384.56 .2018 .814 .0042 & Encontra-se em diligência. Não há denúncia & Não há sentença \\
\hline
\end{tabular}

Fonte: Sistema Libra do Tribunal de Justiça do Estado do Pará

Nota: (*) Posição em agosto de 2019 = processos ativos desde $2009+$ processos julgados, arquivados e baixados entre 2014 e agosto de 2019.

Processos judiciais são documentos que historiam um conjunto de evidências a respeito de alguma situação de fato, na qual existe conflito de interesses entre as partes. Por essa razão, são fontes de referências importante para a investigação científica, revelando casos exemplares para um estudo completo.

Uma primeira constatação desse estudo é que é muito pequeno o número de processos na Comarca, diferente do esperado, uma vez que a imprensa tem reiteradamente publicado matérias para denunciar a violência sexual contra crianças e adolescentes no Marajó. Já foram criadas duas Comissões Parlamentar de Inquérito (CPI) no país para apurar a dimensão e a gravidade desses casos: em 08 de dezembro de 2008, na Assembleia Legislativa do Estado do Pará (ALEPA), e em 9 de fevereiro de 2012, na Câmara dos Deputados.

O baixo quantitativo, então, evidencia que a luta pelo reconhecimento da criança e do adolescente como sujeito de direito e o abuso sexual avançou muito pouco na região, podendo ser a falta de informação sobre seus direitos um dos fatores que contribui para esse modesto número, elevando os riscos de violações.

Para aprofundar o estudo de caso, que é uma investigação empírica, passou-se à análise e discussão das duas sentenças que condenaram os acusados: processo de $\mathrm{n}^{\circ} 0004534$ 06.2014.814.0042 e o processo de $\mathrm{n}^{\mathrm{o}}$ 0003370-98.2017.814.0042.

O estudo mostrou que o primeiro processo transcorreu dentro do princípio da legalidade, do contraditório e da ampla defesa. A denúncia foi recebida da forma como determina o procedimento legal. Foi realizada a audiência de instrução e julgamento, tendo o acusado sido condenado a 8 anos de prisão.

A sentença do processo de $\mathrm{n}^{\circ}$ 0004534-06.2014.814.0042 assim dispõe:

Posto isto, acolho a acusação oferecida pelo Ministério Público contra XXXXXX, que, através de sua conduta ilícita, praticou ao tempo dos fatos o crime tipificado no 217-A do CP, para o fim de condená-lo nas sanções legais. Dosimetria da Pena. Impõe-se a análise das circunstâncias judiciais contidas no art. 59, do CPB, assim disposta: A culpabilidade do acusado é normal ao delito em tela, nada a valorar. Não há registro de condenação anterior em seus antecedentes criminais, não há o que valorar. Quanto à conduta social do agente, nada a valorar. De sua personalidade nada foi aferido nos autos. O motivo do crime é inerente ao tipo penal em espécie, dessa forma não há o que valorar. As circunstâncias e consequências são normais à 
espécie. Nada há de se aferir em relação ao comportamento da vítima. Desta forma, fixo a pena inicial em 08 (oito) anos de reclusão. Não há agravante ou atenuante a ser reconhecida e aplicada. Não há minorante ou causa de aumento de pena. Assim torno definitiva a reprimenda em 8 (oito) anos de reclusão. Detração penal (art. $1^{\circ}$, da Lei $\mathrm{n}^{\circ} 12.736 / 2012$ ). O réu respondeu ao processo em liberdade, não havendo assim possibilidade de detração penal. Seu regime inicial será o FECHADO. Da prisão provisória como não houve encarceramento cautelar e não ocorrendo fato novo que autorize o decreto de sua prisão preventiva, deve responder em liberdade até o trânsito em julgado desta decisão. Provimentos finais. Após o trânsito em julgado da sentença, lance-se o nome dos Réu no Rol de Culpados, encaminhando-se à Secretaria Criminal para fins de execução da pena e anotação da presente condenação no registro de antecedentes no sistema LIBRA, arquivando-se em seguida. Oficie-se ao TRE para aplicação do art. 15 , item III, da $\mathrm{CF} / 88$, acompanhado de cópia da presente decisão. Ciência ao Ministério Público e ao Réu, pessoalmente. Devem permanecer os autos sob segredo de justiça. Intimem-se. Ponta de Pedras/PA, 27 de outubro de 2017.

Como o réu não tinha sido preso durante a instrução, foi lhe concedido o direito de recursar em liberdade até o trânsito e julgado da decisão. Constata-se, então, os direitos do condenado sendo resguardados, como o direito da não culpabilidade e de recorrer em liberdade. No entanto, contata-se também que a vítima teve os seus direitos lesionados, uma vez que o Estado (juiz) não realizou seu encaminhamento para atendimento especializado, apesar de a mesma ter sofrido abuso sexual.

No segundo caso, foram observadas características semelhantes ao anterior e à maioria dos processos pesquisados: o relato do abuso sexual foi encaminhado à Delegacia de Polícia e iniciado o inquérito policial. A vítima, de 8 anos de idade, confirmou o abuso sexual em depoimentos na Delegacia. Após a prisão temporária do réu foi concluído o inquérito policial, realizado o envio do mesmo ao Poder Judiciário, logo em seguida distribuído para o representante do Ministério Público da Comarca, que ofereceu denúncia.

Recebida a denúncia pelo Poder Judiciário, a sentença proferida no processo $\mathrm{n}^{\mathrm{o}}$ 0003370-98.2017.814.0042 indicou a condenação do acusado a uma pena de 09 anos de reclusão em regime fechado:

Isto posto, JULGO PROCEDENTE A PRETENSÃO PUNITIVA DO ESTADO para CONDENAR o acusado R N F P, nos autos qualificado, pela prática do crime de estupro de vulnerável, tipificado no artigo 217-A, do Código Penal. Aprecio as circunstâncias judiciais: A culpabilidade em grau normal para o tipo, que já prevê sanção bastante grave; o denunciado responde a outros processos, não havendo informação quanto à existência de sentença penal condenatória; Conduta social e personalidade do denunciado desajustadas, pois responde a outros processos; motivos do crime, pelo que se infere dos autos, foi a obtenção da vantagem sexual; as circunstâncias e consequências justificam a exasperação da pena, pois o acusado estuprou a sobrinha de sua companheira, uma criança de apenas 8 (oito) anos, a quem deveria proteger; não se pode imputar responsabilidade à vítima pela ocorrência do 
crime, tendo em vista a sua especial condição de vulnerabilidade e que deveria ser destinatária de proteção. O réu é pobre. Assim, atento às circunstâncias analisadas, fixo a pena base em 9 (nove) anos de reclusão, que torno definitiva, por não haver circunstâncias atenuantes ou agravantes ou causas de aumento ou diminuição de pena. $\mathrm{O}$ regime para o cumprimento da pena privativa de liberdade será inicialmente o fechado, por se

tratar de crime hediondo, em conformidade com o que dispõem os artigos $1^{\circ}$ e $2^{\circ}, \S$ $1^{\circ}$, da Lei 8.072/90. Asseguro a detração da pena pelo tempo em que o acusado permaneceu preso provisoriamente para todos os efeitos. Estando presentes os pressupostos que autorizam a prisão preventiva do acusado, especialmente como garantia da ordem pública, como exposto acima, mantenho a sua segregação cautelar. Sem custas, vez que o réu é pobre. Caso haja a interposição de recurso, expeça-se a guia de execução provisória. Após o trânsito em julgado (CF, art. 5, LVII): a) Lancese o nome do réu no rol dos culpados (CPP, art. 393, II); b) Expeça-se o que for necessário para a execução definitiva da pena; c) Oficie-se à Justiça Eleitoral para fins de suspensão dos direitos políticos do réu ( $\mathrm{CF}$, art. 15, III); d) Façam-se as demais comunicações de estilo; e e) Após, arquivem-se os autos. Mantenha-se o processo em segredo de justiça para preservar a intimidade da vítima, podendo, no entanto, ser publicada o dispositivo da sentença no Diário da Justiça Eletrônico para intimação da defensora do acusado.

No entanto, apesar da condenação do acusado, a sentença revela que não foi determinada qualquer medida de proteção social, apenas a de não aproximação do acusado perante a vítima do delito.

Assim, o estudo mostrou que os processos criminais consultados possuem características semelhantes e concorrentes, sendo possível observar que os magistrados restringiram as sentenças à punição do acusado no processo judicial, não tendo sido efetuada a proteção social da vítima.

O Quadro I também mostra que, nos processos pesquisados, o enfoque na proteção social da vítima ocorreu, parcialmente, apenas o processo de $\mathrm{n}^{\circ}$ 0004813.26.2013.8.14.0042. $\mathrm{Na}$ deliberação da audiência de instrução e julgamento, o magistrado determinou, em 26/11/2015, que fosse encaminhado ofício para que o CRAS do município de Ponta de Pedras prestasse atendimento a vítima o mais breve possível. Apesar de esse pedido ter sido reiterado em 18/08/2016, 3 anos após a determinação ainda não foram encaminhadas as informações para a proteção da vítima, estando o processo paralisado.

Nos demais processos, por fim, a análise dos documentos também evidenciou que não há a proteção social da criança e do adolescente pelas diferentes instâncias de atendimento, revelando efetivas faltas de proteção social das vítimas no processo judicial e após a prolação da sentença. 


\section{CONSIDERAÇÕES FINAIS}

Artigo mostrou que a violência sexual é um problema que atinge muitas crianças e adolescentes no arquipélago do Marajó (PA), sendo importante que o Estado garanta seu direito ao reconhecimento dos mesmos como sujeitos de direito.

Entretanto, a análise de sentenças de processos judiciais de estupro de vulnerável na Comarca de Ponta de Pedras revelou uma falta de proteção social das vítimas, apesar dos enormes danos para sua saúde, sobrevivência e dignidade, como atesta a literatura.

Dos oito processos da Comarca de Ponta de Pedras, o estudo encontrou apenas duas condenações. Nos demais, ou a sentença ainda não foi proferida ( 5 casos) ou o agressor foi absolvido. Esse pequeno número de processos contraria as denúncias da $\mathrm{CNBB}$ e os dados levantados em duas CPIs (ALEPA e Câmara dos Deputados) criadas para tratar o problema. Evidencia também que ainda há um longo caminho a percorrer na luta pelo reconhecimento da criança e do adolescente como sujeito de direito na região, uma vez que é insignificante o acesso das mesmas ao judiciário.

$\mathrm{Na}$ análise das duas sentenças condenatórias encontradas, observou-se que os direitos dos condenados foram resguardados, mas as vítimas tiveram os seus direitos lesionados, na medida em que não foram encaminhadas para atendimento especializado, apesar do abuso sexual sofrido. Assim, as sentenças limitaram-se à responsabilização penal do acusado, carecendo o reconhecimento da vítima como sujeito de direito, como defende Honneth (2003).

Como mostrado, a preocupação com a proteção social da vítima ocorreu em apenas um processo, quando foi determinado que o CRAS do município de Ponta de Pedras prestasse atendimento à vítima. Apesar do pedido de urgência, no entanto, não há registros sobre esse atendimento no processo, quase quatro anos após a determinação. O processo está paralisado.

Assim, a falta de reconhecimento e a violência estão relacionados tanto às circunstâncias em que aconteceu o abuso sexual, quanto na ausência de proteção durante o processo judicial e após a sentença, podendo trazer sérios prejuízos no desenvolvimento da criança e adolescente e uma sensação de descrédito nas instituições que são responsáveis pela proteção dessas vítimas.

Dessa forma, apesar da enorme importância do Poder Judiciário nessa rede de proteção, ele vem falhando no papel de garantidor de direitos assegurados pela Constituição 
Federal e pelo Estatuto da Criança e Adolescente para eles tenham proteção integral e condições dignas para um crescimento saudável.

\section{REFERÊNCIAS}

EISENSTEIN, Evelyn. Quebrando o silêncio sobre o abuso sexual. Adolescência e Saúde, vol. $1, n^{\circ} 3,2004$, p. 26-29.

FALEIROS, Eva T. Silveira. Repensando os conceitos de violência, abuso e exploração sexual de crianças e adolescentes. Brasília: Thesaurus. 2000.

FAPESPA - FUNDAÇÃO AMAZÔNIA DE AMPARO A ESTUDOS E PESQUISAS. PPA 2016-2019 - Perfil das Região de Integração. Belém: 2015. Disponível em: http://www.fapespa.pa.gov.br/produto/diagnosticos/88?\&mes=\&ano=2015. Acesso em $10 \mathrm{jul}$. 2019.

FAPESPA - FUNDAÇÃO AMAZÔNIA DE AMPARO A ESTUDOS E PESQUISAS. Região de Integração do Marajó. Perfil Socioeconômico e Ambiental. Belém: 2019. Disponível em: $\quad$ http://www.seplan.pa.gov.br/sites/default/files/PDF/ppa/ppa20202023/ri_marajo.pdf. Acesso em 10 jul. 2019.

HONNETH, Axel. Redistribution as recognition: a response to Nancy Fraser. In: FRASER, Nancy; HONNETH, Axel. Redistribution or recognition? A political philosophical exchange. Trad. Joel Golb; James Ingram; Christiane Wilke. London: Verso, 2003.

INSTITUTO DE PESQUISA ECONÔMICA APLICADA (IPEA). FÓRUM BRASILEIRO DE SEGURANÇA PÚBLICA (FBSP). Atlas da Violência. Rio de Janeiro: 2018. Disponível em http://www.ipea.gov.br/portal/index.php?option=com content\&view=article\&id=33410 \&Itemid=432. Acesso em: 2 mai. 2019.

LEÃO, André. CNBB alerta para aumento de casos de abuso e exploração sexual de crianças no Marajó. Disponível em: https://alpn00.jusbrasil.com.br/noticias/474477985/cnbb-alerta-para-aumento-de-casos-deabuso-e-exploracao-sexual-de-criancas-no-marajo. Acesso em: 5 jul. 2019.

LIMA, Joana Azevêdo; ALBERTO, Maria de Fatima Pereira. As vivências maternas diante do abuso sexual intrafamiliar. Estudos de Psicologia, v. 15, n. 2, p. 129-136, 2010.

MÉLlO, Ricardo Pimentel. A Construção da Noção de Abuso Sexual Infantil. Belém: EDUFPA, 2006.

MONTEIRO, Evanildo Lopes. Do poder pastoral à delinquência: o professor enquanto agente do abuso sexual de crianças e adolescentes. Programa de Pós-Graduação em Educação da Universidade Federal do Pará. Doutor em Educação. 2017. http://ppgedufpa.com.br/arquivos/File/teseevanildo.pdf 
NEVES, Anamaria Silva. CASTRO, Gabriela Brito de; HAYECK, Cynara Marques; CURY, Daniel Gonçalves. Abuso sexual contra a criança e o adolescente: reflexões interdisciplinares. Temas psicol., Ribeirão Preto, v. 18, n. 1, p. 99-111, 2010.

OLIVEIRA, Denise Cabral Carlos de. RUSSO, Jane Araujo. Abuso sexual infantil em laudos psicológicos: as "duas psicologias". Physis Revista de Saúde Coletiva. V. 27, n. 3, 2017, p. $579-604$.

PINTO, Celi Regina Jardim. O que as teorias do reconhecimento têm a dizer sobre as manifestações de rua em 2013 no Brasil. Soc. estado., Brasília , v. 31, n. spe, p. 10711092, 2016.

RIBEIRO, Márcia Aparecida; FERRIANI, Maria das Graças Carvalho; REIS, Jair Naves dos. Violência sexual contra crianças e adolescentes: características relativas à vitimização nas relações familiares. Cad. Saúde Pública, Rio de Janeiro , v. 20, n. 2, p. 456-464, Apr. 2004

SÁ, Mariana Oliveira de. Axel Honneth e a luta por reconhecimento: a fundamentação da resistência política com base na tríade amor, direito e solidariedade. In: Conpedi; Ufsc. (org.). XXII encontro nacional do Conpedi: (re) pensando o direito: desafio para construção de novos paradigmas. 1ed. Florianópolis: Conpedi, 2014, v. 1, p. 275-297. Disponível:em:< http://www.publicadireito.com.br/conpedi/anais.php >. Acesso em: 19 abr. 2019.

SARMENTO, Daniel, Dignidade da pessoa humana, conteúdo, trajetória e metodologia. Belo Horizonte: Ed. Forúm, 2016.

WORLD HEALTH ORGANIZATION (WHO). World report on violence and health. Geneva: WHO, 2002. 